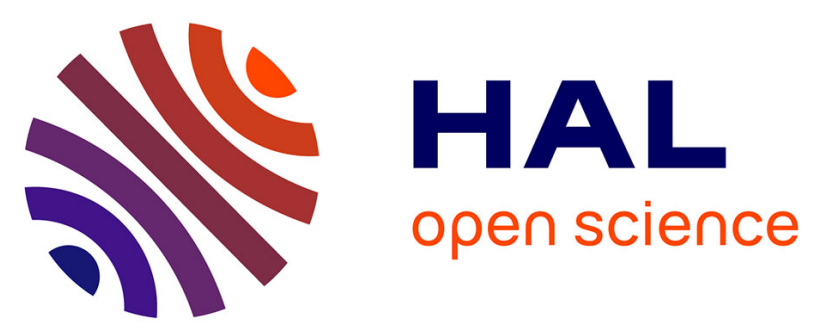

\title{
Nano-litter from cigarette butts: Environmental implications and urgent consideration
}

Quentin Chevalier, Hind El Hadri, Patrice Petitjean, Martine Bouhnik-Le Coz, Stephanie Reynaud, Bruno Grassl, Julien Gigault

\section{To cite this version:}

Quentin Chevalier, Hind El Hadri, Patrice Petitjean, Martine Bouhnik-Le Coz, Stephanie Reynaud, et al. Nano-litter from cigarette butts: Environmental implications and urgent consideration. Chemosphere, 2018, 194, pp.125-130. 10.1016/j.chemosphere.2017.11.158 . insu-01652616

\section{HAL Id: insu-01652616 https://hal-insu.archives-ouvertes.fr/insu-01652616}

Submitted on 30 Nov 2017

HAL is a multi-disciplinary open access archive for the deposit and dissemination of scientific research documents, whether they are published or not. The documents may come from teaching and research institutions in France or abroad, or from public or private research centers.
L'archive ouverte pluridisciplinaire HAL, est destinée au dépôt et à la diffusion de documents scientifiques de niveau recherche, publiés ou non, émanant des établissements d'enseignement et de recherche français ou étrangers, des laboratoires publics ou privés. 


\section{Accepted Manuscript}

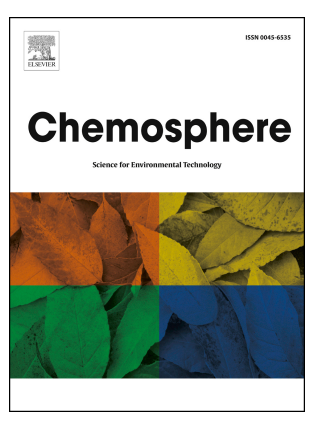

Nano-litter from cigarette butts: Environmental implications and urgent consideration

Quentin Chevalier, Hind El Hadri, Patrice Petitjean, Martine Bouhnik-Le Coz,

Stéphanie Reynaud, Bruno Grassl, Julien Gigault

PII: S0045-6535(17)31935-5

DOI: $\quad$ 10.1016/j.chemosphere.2017.11.158

Reference: CHEM 20355

To appear in: $E C S N$

Received Date: 25 August 2017

Revised Date: 18 November 2017

Accepted Date: 26 November 2017

Please cite this article as: Chevalier, Q., El Hadri, H., Petitjean, P., Bouhnik-Le Coz, M., Reynaud, Sté., Grassl, B., Gigault, J., Nano-litter from cigarette butts: Environmental implications and urgent consideration, Chemosphere (2017), doi: 10.1016/j.chemosphere.2017.11.158.

This is a PDF file of an unedited manuscript that has been accepted for publication. As a service to our customers we are providing this early version of the manuscript. The manuscript will undergo copyediting, typesetting, and review of the resulting proof before it is published in its final form. Please note that during the production process errors may be discovered which could affect the content, and all legal disclaimers that apply to the journal pertain. 
1 Nano-litter from cigarette butts: environmental implications and urgent

2 consideration

Quentin Chevalier ${ }^{1}$, Hind El Hadri ${ }^{2}$, Patrice Petitjean ${ }^{1}$, Martine Bouhnik-Le Coz ${ }^{1}$, Stéphanie Reynaud $^{2}$, Bruno Grassl ${ }^{2}$, Julien Gigault* ${ }^{1}$

${ }^{1}$ Laboratoire Géosciences Rennes

CNRS-Université de Rennes 1

263 avenue Général Leclerc - Campus Beaulieu - Bât 15

35000 Rennes

${ }^{2}$ Institut des sciences analytiques et de physico-chimie pour l'environnement et les matériaux CNRS-Université de Pau et des Pays de l'Adour

2 avenue P. Angot - Technopôle Hélioparc $64000 \mathrm{Pau}$

*Corresponding author:

Tel.: +33(0)223235356

Email: julien.gigault@univ-rennes1.fr

\section{Abstract}

Cigarette butts (CGB) are equivalent to plastic litter in terms of number of pieces released directly into the environment. Due to their small size and social use, CGB are commonly found in natural systems, and several questions have been raised concerning the contaminants that are released with CGB, including metals, organic species, and nanoparticles. The aim of the present study is to investigate the release of nanoscale particles from CGB by leaching with rainwater. After seven days of passive stirring of both smoked and unsmoked CGB in synthetic rainwater, the solutions were treated and analyzed by specific nano-analytical methods. Our results demonstrate the release of $4.12 \pm 0.24 \%$ (w/CGB) organic carbon in the range of $10 \mathrm{~nm}$ up to $400 \mathrm{~nm}$ and with a z-average diameter of $202.4 \pm 74.1 \mathrm{~nm}$. The fractal dimension $\left(\mathrm{D}_{\mathrm{f}}\right)$ of the nanoscale particles ranges from 1.14 to 1.52 and suggests a soot (carbon)-based composition. The analysis of some metallic species ( $\mathrm{As}, \mathrm{Pb}, \mathrm{Cd}, \mathrm{Cu}, \mathrm{Ni}, \mathrm{Cr}$, $\mathrm{Co}, \mathrm{Al}, \mathrm{Mn}, \mathrm{Zn}$, and $\mathrm{Fe}$ ) shows that these species are essentially attached to the nanoscale 
38 particles per gram of carbon released. By considering the diffusion of the nanomaterials into

39 different environmental compartments, our results suggest a new emerging and global

40 contamination of the environment by cigarette butts, comparable to plastic litter, which

41 urgently needs to be considered.

42

43 Keywords: Environment, Nanoparticles, Cigarette butts, Characterization, Metals

44

45 
47 The principle litter associated with the consumption of cigarettes are smoke and cigarette butts (CGB), i.e., filter compounds and cigarette smoke (Healton et al., 2011; Marah and Novotny, 2011; Novotny et al., 2009). While the $\mathrm{CO}_{2}$ contribution of cigarette smoke can be

considered negligible compared to that emitted by other human activities, CGB, like plastic waste, raise many environmental issues. CGB are the most common form of waste found in nature, and over 5.6 trillion cigarette butts can be found in nature each year (Healton et al., 2011). Moreover, CGB found in the environment are likely to release their components to the environment and pollute soils, water and all other environmental compartments. Several studies have shown that several hazardous pollutants are released and leached from CGB, which can have dramatic effects on the environmental and public health (Novotny et al., 2009). Moerman and Potts highlighted the release of several metals from CGB (Cd, As, Ni, $\mathrm{Cu}, \mathrm{Pb}$ and $\mathrm{Zn}$ ) with quantities ranging from few $\mu \mathrm{g} \mathrm{g}^{-1}$ up to several hundred $\mu \mathrm{g} \mathrm{g}^{-1}$ (Moerman and Potts, 2011), which has also been confirmed elsewhere (Dobaradaran et al., 2017; Pelit et al., 2013). However, to the best of our knowledge, no data are currently available concerning both their release and transport mechanisms. Recently, a new class of nanoscale contaminants have been considered classified as accidental nanoparticles from anthropogenic source such as nanoplastics (Koelmans et al., 2015; Ter Halle et al., 2017). Due to the recent and emerging risk of nanoparticles (Baalousha et al., 2016; BystrzejewskaPiotrowska et al., 2009), questions have been raised about these new nanoscale contaminants and their possible release from CGB. Recently, authors have measured the air transfer of soot nanoparticles with sizes under $50 \mathrm{~nm}$ from the partial combustion of cigarettes into the human pulmonary system (van Dijk et al., 2011). Based on this preliminary study, it is possible to imagine the presence of nanoscale particles concentrated in CGB that could potentially leach into the environment. According to the number of CGB released into the environment, there is 
71 a considerable lack of available data on the nanoscale risk associated with CGB. The main questions, therefore, are which nanoparticles (size, composition) are concentrated in CGB and whether these nanoparticles are released into the environment. Due to their intrinsic properties, such as size and surface area, nanoscale particles are known to transport a large quantity of adsorbed species, such as metals and organic contaminants, along different environmental compartments and in living organisms (Velzeboer et al., 2014; Wang et al., 2013). The main concern with nanoscale particles is their ability to penetrate different natural barriers to deliver the species adsorbed to their surface.

The aim of this paper is to demonstrate the release of nanoscale particles (NP) from cigarette butts by leaching with rainwater, followed by their chemical and physical characterization. Different high-resolution analytical techniques, such as in situ dynamic light scattering (ISDLS) and asymmetrical flow field-flow fractionation coupled to light scattering detection (A4F-UV-SLS), were optimized for nanoscale particle characterization to measure key parameters such as size distribution, aggregation information, fractal dimension, and elemental composition. Our results demonstrate that a large distribution of NP sizes and structures are released. The metal distribution associated with the NP fraction raised several environmental concerns that urgently need to be considered. We hope that our results will help tobacco control agencies to consider this type of environmental and health exposure from cigarette litter.

\section{Materials and methods}

\subsection{Sample preparation}

A fresh synthetic rainwater (FSRW) sample was prepared according to Davies et al. (Davies et al., 2004). Briefly, the rainwater has an ionic strength of $0.3 \times 10^{-3} \mathrm{~mol} \mathrm{~L}^{-1}$, and the following components comprise 1 liter, which was then diluted by a factor of 1,000: $\mathrm{NaNO}_{3}$, 
$4.07 \mathrm{~g} ; \mathrm{NaCl}, 3.24 \mathrm{~g} ; \mathrm{KCl}, 0.35 \mathrm{~g} ; \mathrm{CaCl}_{2} \cdot 2 \mathrm{H}_{2} \mathrm{O}, 1.65 \mathrm{~g} ; \mathrm{MgSO}_{4} \cdot 7 \mathrm{H}_{2} \mathrm{O}, 2.98 \mathrm{~g}$; and $\left(\mathrm{NH}_{4}\right)_{2} \mathrm{SO}_{4}, 3.41 \mathrm{~g}$. The resulting solution had a $\mathrm{pH}$ of 5.2. More than 12 kilograms of cigarette butts (CGB) were collected over one year after immediate consumption from three different places in Rennes (Brittany, France). CGB were collected directly after consumption and placed directly in a plastic container under vacuum into a fridge $\left(4^{\circ} \mathrm{C}\right)$. No CGB were collected on the ground to avoid bias measurement in the leaching experiment. For a single experiment, four CGB were randomly chosen, cleaned of old tobacco and placed into a $15 \mathrm{~mL}$ conical vial (previously rinsed by $\mathrm{HNO}_{3} 10 \%$ (w/v) and DI water to remove any trace of $\mathrm{HNO}_{3}$ ). Then, $10 \mathrm{~mL}$ of FSRW was added into the conical vial. Then, the vials were placed on a rotator stirring at $30 \mathrm{rpm}$ under classical light conditions for 7 full days. Then, the leached solutions were filtered at $0.45 \mu \mathrm{m}$ and stored in the fridge. A small fraction of the solutions was kept for total metal and organic carbon analysis. The remaining volumes were concentrated and size-fractionated by an ultrafiltration cell (Amicon®), Millipore, France) with a 10,000 Dalton (10 kDa) molecular weight cut-off (MWCO) membrane made of polyethersulfone (Nadir, Alting, Metz, France). The retentates were concentrated three times and rinsed by three equivalent volumes of FSRW. The same procedure was followed for unsmoked CGB (un-CGB). The CGB leaching experiments were repeated more than 5 times, and the final volume was concentrated more than 20 times and rinsed 3-4 times by FSRW. All experiments were repeated identically 6 times for each condition in order to obtain convenient statistical results.

\subsection{Reagent}

The employed reagents were of analytical grade. The reagents to prepare the synthetic rainwater and the $\mathrm{HNO}_{3}$ used for the digestion procedure were of ultra-trace pure quality (Labbox, Rungis, France). All plastic and glassware were cleaned by soaking in a $10 \%(w / v)$ 
$121 \mathrm{HNO}_{3}$ solution and then rinsed with DI water before use. All solutions were prepared using

122 ultrapure water (MilliQ, $18.2 \mathrm{~m} \Omega \mathrm{cm}$ ).

123

124

125

126

127

128

129

130

131

132

133

134

\subsection{Elemental analysis}

Total organic carbon analysis was performed using a TOC analyzer from Shimadzu (Paris, France). The metal concentrations were determined by ICP-MS using an Agilent Technologies 7700x instrument. The samples were pre-digested with $\mathrm{HNO}_{3}$ to avoid any interference from organic carbon during the analysis. A flux of He was injected in a collision cell to remove interferences. Quantitative analyses were performed using a conventional external calibration procedure (seven external standard multi-element solutions, Inorganic Venture, USA). Rhodium-rhenium was added on-line as an internal standard at a concentration of $300 \mathrm{ppb}$ to correct for instrumental drift and possible matrix effects. Calibration curves were calculated from the intensity ratios of the internal standard and the analyzed elements. The international geostandard SLRS-4 was used to control the accuracy and reproducibility of the measurement procedure. The instrumental error of metal analysis was below 3\%. The metal concentrations in the blanks were lower than the detection limits, and thus, no correction was needed.

\subsection{Nanoscale particle characterization}

In the present case, IS-DLS was used to detect the presence of nanoscale particles in the aqueous system. In DLS, due to the Brownian motion of nanoscale particles, time-dependent fluctuations of the scattered light intensity are measured. These fluctuations allow the determination of the dynamics of the scattering particles (Burchard, 1983). The timedependent fluctuations are transformed into the auto-correlation function (ACF), which for nanoscale particles in a solution, decays with a relaxation rate directly correlated to the 
146 diffusion coefficient $\mathrm{D}\left(\mathrm{m}^{2} \mathrm{~s}^{-1}\right)$ and therefore, the hydrodynamic size according to the stokes-

147 Einstein equation is:

$$
D=\frac{k_{B} T}{3 \pi \eta d_{H}}
$$

148 where $d_{H}$ is the hydrodynamic diameter, $\eta$ is the viscosity of the mobile phase $\left(\mathrm{kg} \mathrm{m}^{-1} \mathrm{~s}^{-1}\right), \mathrm{T}$

149 is the temperature of the medium (at room temperature, $293 \mathrm{~K}$ ) and $\mathrm{k}_{\mathrm{B}}$ is the Boltzmann 150 constant $\left(1.3810^{-23} \mathrm{~kg} \mathrm{~m}^{2} \mathrm{~s}^{-2} \mathrm{~K}^{-1}\right)$. The IS-DLS instrument used in this study is a Vasco Flex 151 from Cordouan Technologies (Pessac, France) and allows the measurement of particles 152 directly in the solution (see ESI-S1). Asymmetrical flow field-flow fractionation (A4F), a liquid-chromatography-based technique, coupled to UV-Vis and static light scattering (SLS) was used to obtain highresolution size and structure characterizations. The A4F system used in this investigation is an Eclipse 3+ from Wyatt Technology (Dernbach, Germany). The trapezoidal A4F channel was $15726.5 \mathrm{~cm}$ in length, 0.6 and $2.1 \mathrm{~cm}$ in width, and had a thickness fixed here at $250 \mu \mathrm{m}$. The A4F fractionation conditions are optimized according to the protocol described elsewhere (Gigault et al., 2014) and summarized as follows: detector flow fixed at $0.5 \mathrm{~mL}$ min-1; relaxation flow fixed at $2.0 \mathrm{~mL} \mathrm{~min}^{-1}$ during 5 minutes; the elution starts with a decreasing crossflow rate (exponential decay) from 2.0 to 0.1 within 40 minutes. The A4F is coupled to a 162 UV-Vis absorbance diode array detector from Agilent Technologies (Les Ulis, France) and a static light scattering (SLS) detector (Dawn Heleos) from Wyatt Technology (Santa Barbara, CA, USA). The SLS principle consists of measuring the intensity of light scattered by the particles according to the angle of detection (Burchard, 1983). Briefly, the SLS signal depends on both the concentration and size (gyration radius, $R_{g}$ ) of the analytes. $R_{g}$ is defined as the square root of the weighted average of the distance for all mass points inside a given analyte (Burchard, 1983). Additionally, from SLS and the angular variation in the intensity of scattered light, the fractal dimension $\left(D_{f}\right)$ can be determined (Raper and Amal, 1993). With 
170 regard to nanoparticles, $D_{f}$ is a precise indication of both the shape and porosity of the 171 materials (see ES-S3). Discrete measurement results are reported as the mean with an 172 associated uncertainty of one standard deviation (presented as an interval or error bar) and are 173 typically based on three to five replicates performed under repeatable conditions.

174

\section{Results and discussion}

After the seven-day leaching experiment, the total organic carbon (TOC) in the unsmoked (un-CGB) and smoked-cigarette butts (f-CGB) was measured to be $2.81 \pm 0.36 \%$ (w/CGB) and $4.12 \pm 0.24 \%$ (w/CGB), respectively. To normalize and compare the results, the TOC values are expressed as the dry weight percentage related to the total mass of CGB used in the leaching experiment (w/CGB). Figure 1 presents the results obtained by IS-DLS. Even if a relative quantity of TOC is released from un-CGB, no correlation in the intensity of scattered light is observed in the ACF (blue dot in Fig. 1a). At this TOC concentration, a constant ACF close to unity is characteristic of the absence of nanoscale particles in the solution. After concentration by ultrafiltration at $10 \mathrm{kDa}$, again, correlation in the ACF is still lacking, suggesting that all the carbon materials released from un-CPG are molecular and dissolved or are under the size limit for DLS characterization (evaluated at $1 \mathrm{~nm}$ ). Because cigarette filters are mostly composed of cellulose-based materials, the release of these materials (degraded or not) is expected (Bonanomi et al., 2015). In contrast, for f-CGB, the increase in the TOC to $4.12 \pm 0.24 \%$ (w/CGB) is directly correlated with the distinct exponential decay of the ACF. Based on this ACF and according to the DLS theory, Figure 1b illustrates the hydrodynamic diameter distribution of different leachate replicates. As expected by the filtration cut-off $(0.45 \mu \mathrm{m}), \mathrm{d}_{\mathrm{H}}$ ranges from 70 to $400 \mathrm{~nm}$ with a maximum from 180 to $220 \mathrm{~nm}$ and a $\mathrm{z}-$ average of $\mathrm{d}_{\mathrm{zH}}=202.4 \pm 74.1 \mathrm{~nm}$. 

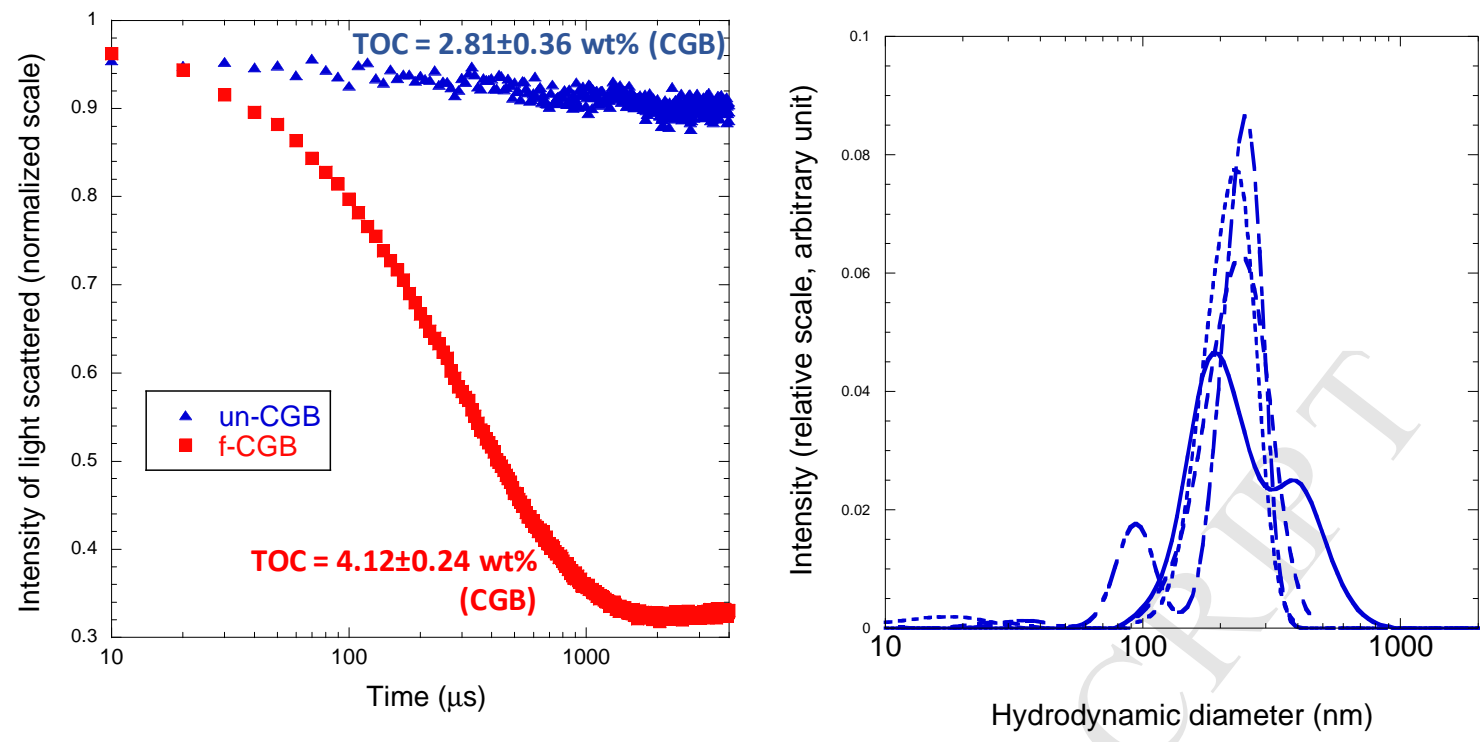

Figure 1: Dynamic light scattering results of smoked and unsmoked cigarette butt leachate with (a) the autocorrelation function and $(b)$ the corresponding size distribution of the different leaching experiments replicates. The total organic carbon (TOC) is indicated on the ACF.

Figure $2 \mathrm{a}$ and $2 \mathrm{~b}$ presents the fractogram obtained by A4F-UV-SLS with light scattering traces at $90^{\circ}$ (Fig. 2a) and UV absorbance at $254 \mathrm{~nm}$ (Fig. 2b). In normal-mode elution, A4F separates particles according to the coefficient of diffusion and linearly according to the hydrodynamic size. The UV trace presents a large peak in the void time (at lower retention time, $\mathrm{t}_{0}=1 \mathrm{~min}$ ) corresponding to un-retained species, generally dissolved species but with sizes over $10 \mathrm{kDa}$. Degraded cellulose from the cigarette filter or other small molecules from the combustion process can be included in this small size fraction. Additionally, in the UV trace at this void time, no size information can be obtained from SLS, characteristic to particles with radii less than $10 \mathrm{~nm}$ (size limit of SLS detection). At higher retention time (i.e., 18 minutes), the UV trace presents a second small peak relative to the void time, correlated to a large and intense SLS trace. This second retained population can be attributed to nanoscale particles with a smaller relative proportion than the dissolved portion. This difference can be explained by the dependency of the SLS detector on both the analyte 211 concentration and size $\left(\mathrm{r}^{6}\right)$. The gyration radius $\left(\mathrm{R}_{\mathrm{g}}\right)$ of the nanoscale particle population ranges from $70 \mathrm{~nm}$ to $280 \mathrm{~nm}$. 
Based on both the DLS and A4F-SLS results, the maximum size determined

214 corresponds to the filtration cut-off $(0.45 \mu \mathrm{m})$. Nevertheless, at the lower size regime, no

215 particles with sizes below $70 \mathrm{~nm}$ in diameter are characterized, raising several questions

216 concerning their presence and/or the limitation of the analytical methods. In a recent

217 publication, van Dijk et al. highlighted that nanoparticles with sizes ranging from $6 \mathrm{~nm}$ to 50

$218 \mathrm{~nm}$ from cigarette smoke transfer to humans (van Dijk et al., 2011). Such results indicate that

219 the filters in cigarette butts cannot concentrate nanoparticles with sizes below $50 \mathrm{~nm}$

220 (approximately). As demonstrated above, because sizes lower than $70 \mathrm{~nm}$ were not detected

221 in the CGB leachate, a hypothesis for their absence in CGB and their ability to pass through

222 the filter can be made, confirming literature data and validating our size determination results. 

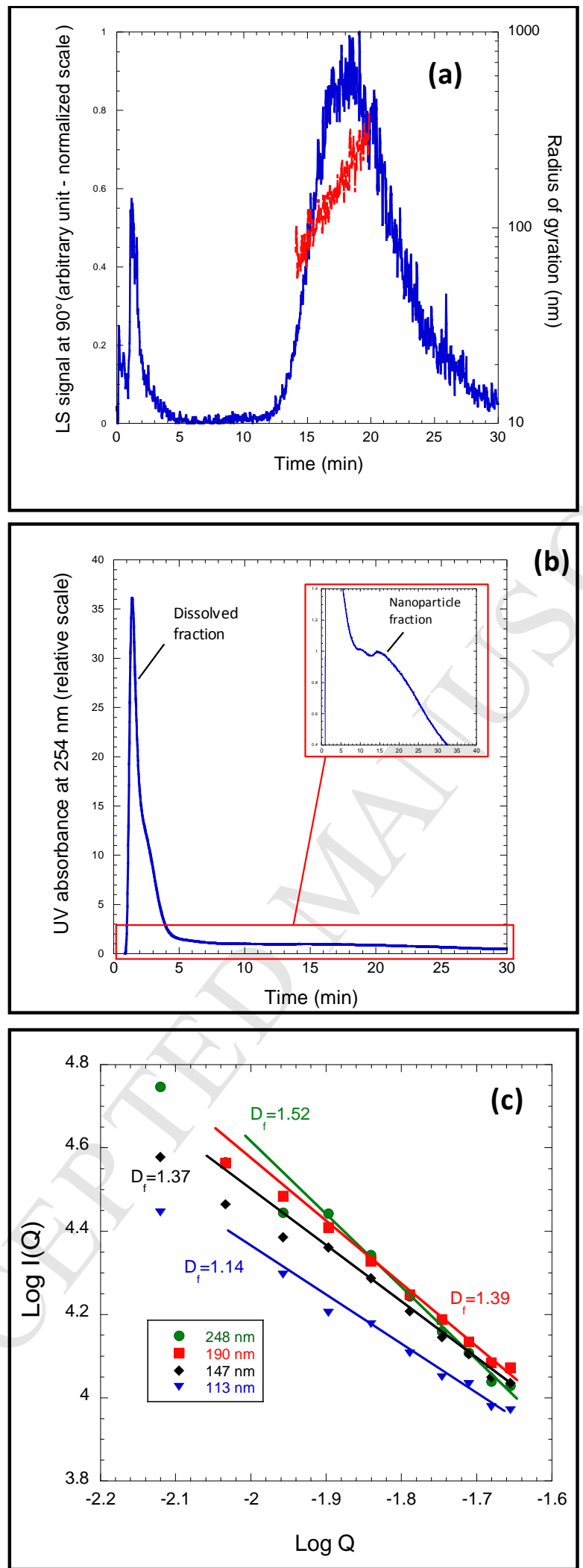

Figure 2: A4F analysis of nanoscale materials released from $f$-CGB: (a) the SLS trace and the $r_{G}$ variation according to retention time, (b) the UV trace at $254 \mathrm{~nm}$, and (c) the log-log plot of the scattering vector according to the intensity of the light scattered for different $r_{G}$ values. 
The correlation of the A4F-UV-SLS and IS-DLS results gives information about the

230

231

232

233 shape of the analytes, which can be characterized by the shape ratio expressed as $\mathrm{R}_{\mathrm{g}} / \mathrm{r}_{\mathrm{H}}$. Based on the mean size, the $\mathrm{R}_{\mathrm{g}} / \mathrm{r}_{\mathrm{H}}$ ratio is $1.51 \pm 0.01$. This typical value is characteristic of particles deviating slightly from spherical-shaped or with changing intrinsic structures. Figure 2c presents the variation in the intensity of light according to the scattering vector $(\mathrm{Q})$ on the log$\log$ scale (Gigault and Grassl, 2017). For $\mathrm{Q} \times \mathrm{R}_{\mathrm{g}}>1$, the slope is directly related to the fractal dimension $\left(D_{f}\right)$. Nanoscale particles released from f-CGB present highly open structures with a $D_{f}$ of 1.13 for $113 \mathrm{~nm}\left(r_{G}\right)$ particles up to 1.52 for $r_{G}=248 \mathrm{~nm}$. A $D_{f}$ close to 3 corresponds to spherical and compact particles and aggregates, while a $\mathrm{D}_{\mathrm{f}}$ close to unity is characteristic of one-dimensional particles, such as worm-like or other hyper-branched particles. The $\mathrm{D}_{\mathrm{f}}$ values obtained for f-CGB correspond to those obtained in previous works investigating soot aggregation in aqueous system (Gorbunov et al., 1999; Luo et al., 2005; Ma et al., 2013). Due to this similarity with carbon-based nanomaterials, the nanoscale particles released from CGB can be hypothesized to have a soot-based composition.

To investigate the composition of the nanoparticle fraction and validate our previous hypothesis, the leachate was ultrafiltered on a $10 \mathrm{kDa}$ MWCO filter. While the filtrate $(<10$ $\mathrm{kDa}$ ) was considered the dissolved fraction, the retentate was considered the nanoscale particle fraction. The corresponding IS-DLS results are presented in the supplemental information (see ES-Fig. S1). The TOC values of the two fractions are similar to those obtained for the initial solutions without purification. Cigarette smoke is known to transport many contaminants such as polycylic aromatic compounds and heavy metals (GalażynSidorczuk et al., 2008; Järup, 2003; Luceri et al., 1993). 


\section{ACCEPTED MANUSCRIPT}

Dissolved fraction $(<10 \mathrm{kDa})$

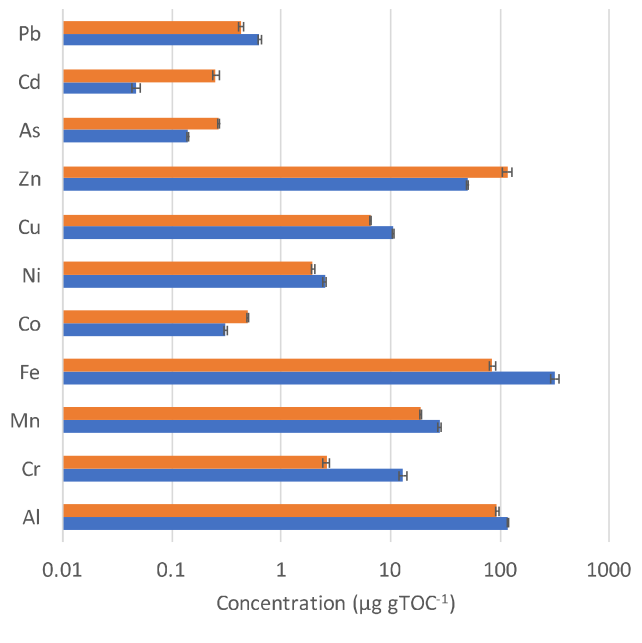

- $\mathrm{f}-\mathrm{CGB}$ un-CGB

Nanoparticles fraction (>10kDa)
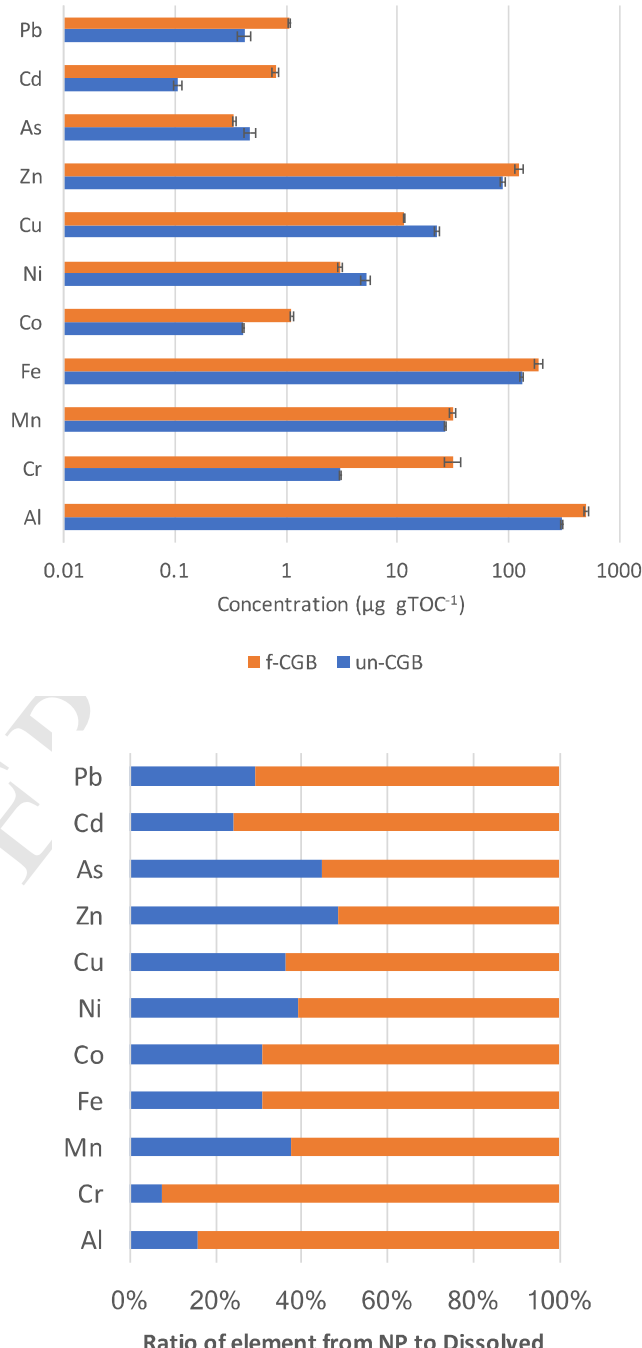

Ratio of element from NP to Dissolved

$$
\text { घ }<10 \mathrm{kDa} \quad \square 10 \mathrm{kDa}
$$
their relative distributions. 
Figure 3 presents the variation in the principal metallic and inorganic species analyzed

257

258

259 by ICP-MS according to both the un-CGB and f-CGB fractions. To compare the results among the different replicates, all concentrations in the rainwater leachate solution were normalized by the amount of total organic carbon analyzed $\left(\mu \mathrm{g} \mathrm{gTOC}^{-1}\right)$ in each fraction. Among all species quantified, $\mathrm{Fe}, \mathrm{Al}$ and $\mathrm{Zn}$ are predominant, with more than $100 \mu \mathrm{g} \mathrm{gTOC}^{-1}$ released. $\mathrm{Cr}, \mathrm{Mn}$ and $\mathrm{Cu}$ are less dominant, with masses ranging from 1 to $50 \mu \mathrm{g} \mathrm{gTOC}^{-1}$ released. Finally, 0.1 to $1 \mu \mathrm{g} \mathrm{gTOC}^{-1}$ of $\mathrm{Pb}, \mathrm{Cd}$, As and Co was released. The total metal concentrations are on the same order of magnitude as those reported in the literature (Moerman and Potts, 2011). Considering the fractional distribution, un-CGB presents metallic concentration, while no nanoparticles were identified and characterized by IS-DLS and A4FSLS. This result is explained by the low MWCO (i.e., $10 \mathrm{kDa}$ ) used to separate and concentrate both fractions by sequential ultrafiltration. As previously explained, cigarette filters are composed of cellulose-based materials (Slaughter et al., 2011). These materials are degraded during the leaching process and released in a large molecular weight distribution but are not sufficiently large $(5-10 \mathrm{~nm})$ to be detected by A4F-UV-SLS and/or DLS. For the dissolved fractions, no distinct differences are observed in the metal distribution of un-CGB and f-CGB. Nevertheless, for the NP fraction, except for $\mathrm{Cu}$, $\mathrm{Ni}$ and $\mathrm{As}$, an increase in metal is observed. f-CGB does not show a different total amount of metal in the leached solution compared to un-CGB but has a distinct effect on their distribution according to the size fraction (i.e., from the dissolved to the nanoscale particle fraction). In Figure 3, the relative proportion of each species characterized is illustrated according to the fraction. Except for As and $\mathrm{Zn}$, which are distributed equally between the two fractions, all other metal species are principally distributed in the NP fraction. These results confirm the high affinity of metal species with carbon-based colloids generally observed in the environment (Dai et al., 1995; 
280

281

282

283

284

285

Hargreaves et al., 2017; Sau et al., 2010; Waeles et al., 2008). A recent work from Hargreaves et al. showed that wastewater effluent contained a considerable distribution of metal $(\mathrm{Cu}, \mathrm{Pb}$, $\mathrm{Ni}$ and $\mathrm{Zn}$ ) in the nanoscale fraction adsorbed and/or complexed with non-humic macromolecules, such as soot nanoparticles (Hargreaves et al., 2017).

Moreover, for $\mathrm{Cr}$ and $\mathrm{Al}$, a clear difference is observed in that over $80 \%$ is associated with the NP fraction. Alumina is known to be both in the colloidal form when in its oxide forms and associated with colloid particles with fractal size distribution, such as soot particles (Ringenbach et al., 1995). Concerning chromium, different hypotheses are made according to its oxidation state $(\mathrm{Cr}(\mathrm{III})$ or $\mathrm{Cr}(\mathrm{VI}))$ within the $\mathrm{pH}$ of rainwater. Soot particles are generally negatively charged, and because the pH of FSRW is slightly acidic, different association can be made. Further analysis to understand the precise speciation of such metals associated with NP released from cigarette butts is on-going. These on-going studies concern the speciation of metals according to the physical and chemical properties of the nanoscale fraction. Additionally, further analyses are also planned to evaluate the stability of such nanoscale particles in different environmental compartments.

Without considering nanoparticles specifically, a large amount of metals is released in the environment from CGB. As illustrated in Figure 4, a rapid estimation could reach several millions of tons each year for both the dissolved and nanoscale fraction.

Currently, NP are difficult to remove in wastewater treatment plants, and most often, this size fraction is directly released into the environment. Knowing the diffusion properties of nanomaterials in different environmental compartments, our results suggest a new emerging and global contamination of the environment by cigarette butts, comparable to plastic litter, which urgently needs to be considered.

Indeed, compared to dissolved species (where metals can be more easily complexed, accumulated and remediated), metals can be massively accumulated in the NP fraction and 
transported over a large distance. Such transport could dramatically increase their environmental and health impacts. Slaughter et al. showed that the toxicity of cigarette butt leachate on marine and freshwater fish increased from un-CGB to f-CGB (Slaughter et al., 2011). Our results can explain this increase and suggest that by improving NP removal from wastewater combined with policies for prohibiting CGB social dumping in both urban and rural systems, an important decrease in the total amount of metal in the environment can be expected.

Figure 4: Estimation of the total worldwide metal released in the environment by year from cigarette butts, according to the fraction considered. *The total estimation is based on the calculation of the global amount of cigarette butts littered each year in the environment made by Healton et al. and considers leaching from rainwater as the only release mechanism.

\section{Acknowledgements}

319 This work is supported by "Observatoire des Sciences de l'Univers de Rennes" of the French 320 National Center for Scientific Research (CNRS). 
322

323

324

325

326

327

328

329

330

331

332

333

334

335

336

337

338

339

340

341

342

343

344

345

346

347

348

349

350

351

352

353

354

355

356

357

358

359

360

361

362

363

364

365

366

367

368

369

\section{References}

Baalousha, M., Yang, Y., Vance, M.E., Colman, B.P., McNeal, S., Xu, J., Blaszczak, J., Steele, M., Bernhardt, E., Hochella Jr., M.F., 2016. Outdoor urban nanomaterials: The emergence of a new, integrated, and critical field of study. Sci. Total Environ. 557-558, 740753.

Bonanomi, G., Incerti, G., Cesarano, G., Gaglione, S.A., Lanzotti, V., 2015. Cigarette Butt Decomposition and Associated Chemical Changes Assessed by 13C CPMAS NMR. PLoS ONE 10.

Burchard, W., 1983. Static and dynamic light scattering from branched polymers and biopolymers, in: Light Scattering from Polymers, Advances in Polymer Science. Springer Berlin Heidelberg, pp. 1-124.

Bystrzejewska-Piotrowska, G., Golimowski, J., Urban, P.L., 2009. Nanoparticles: Their potential toxicity, waste and environmental management. Waste Manag. 29, 2587-2595.

Dai, M., Martin, J.-M., Cauwet, G., 1995. The significant role of colloids in the transport and transformation of organic carbon and associated trace metals $(\mathrm{Cd}, \mathrm{Cu}$ and $\mathrm{Ni})$ in the Rhône delta (France). Mar. Chem. 51, 159-175.

Davies, C.M., Ferguson, C.M., Kaucner, C., Krogh, M., Altavilla, N., Deere, D.A., Ashbolt, N.J., 2004. Dispersion and Transport of Cryptosporidium Oocysts from Fecal Pats under Simulated Rainfall Events. Appl. Environ. Microbiol. 70, 1151-1159.

Dobaradaran, S., Nabipour, I., Saeedi, R., Ostovar, A., Khorsand, M., Khajeahmadi, N., Hayati, R., Keshtkar, M., 2017. Association of metals (Cd, Fe, As, Ni, Cu, Zn and Mn) with cigarette butts in northern part of the Persian Gulf. Tob. Control 26, 461-463.

Galażyn-Sidorczuk, M., Brzóska, M.M., Moniuszko-Jakoniuk, J., 2008. Estimation of Polish cigarettes contamination with cadmium and lead, and exposure to these metals via smoking. Environ. Monit. Assess. 137, 481-493.

Gigault, J., Grass1, B., 2017. Improving the understanding of fullerene (nC60) aggregate structures: Fractal dimension characterization by static light scattering coupled to asymmetrical flow field flow fractionation. J. Colloid Interface Sci. 502, 193-200.

Gigault, J., Pettibone, J.M., Schmitt, C., Hackley, V.A., 2014. Rational strategy for characterization of nanoscale particles by asymmetric-flow field flow fractionation: A Tutorial. Anal. Chim. Acta 809, 9-24.

Gorbunov, B., Clarke, A.G., Hamilton, R.S., 1999. Coagulation of soot particles and fractal dimension. J. Aerosol Sci. 30, S445-S446.

Hargreaves, A.J., Vale, P., Whelan, J., Constantino, C., Dotro, G., Campo, P., Cartmell, E., 2017. Distribution of trace metals $(\mathrm{Cu}, \mathrm{Pb}, \mathrm{Ni}, \mathrm{Zn})$ between particulate, colloidal and truly 
dissolved fractions in wastewater treatment. Chemosphere 175, 239-246.

Healton, C.G., Cummings, K.M., O'Connor, R.J., Novotny, T.E., 2011. Butt really? The environmental impact of cigarettes. Tob. Control 20, i1-i1.

Järup, L., 2003. Hazards of heavy metal contamination. Br. Med. Bull. 68, 167-182.

Koelmans, A.A., Besseling, E., Shim, W.J., 2015. Nanoplastics in the Aquatic Environment. Critical Review, in: Bergmann, M., Gutow, L., Klages, M. (Eds.), Marine Anthropogenic Litter. Springer International Publishing, pp. 325-340.

Luceri, F., Pieraccini, G., Moneti, G., Dolara, P., 1993. Primary Aromatic Amines from SideStream Cigarette Smoke are Common Contaminants of Indoor Air. Toxicol. Ind. Health 9, 405-413.

Luo, C.-H., Lee, W.-M.G., Lai, Y.-C., Wen, C.-Y., Liaw, J.-J., 2005. Measuring the fractal dimension of diesel soot agglomerates by fractional Brownian motion processor. Atmos. Environ. 39, 3565-3572.

Ma, X., Zangmeister, C.D., Gigault, J., Mulholland, G.W., Zachariah, M.R., 2013. Soot aggregate restructuring during water processing. J. Aerosol Sci. 66, 209-219.

Marah, M., Novotny, T.E., 2011. Geographic patterns of cigarette butt waste in the urban environment. Tob. Control 20, i42-i44.

Moerman, J.W., Potts, G.E., 2011. Analysis of metals leached from smoked cigarette litter. Tob. Control 20, i30-i35.

Novotny, T.E., Lum, K., Smith, E., Wang, V., Barnes, R., 2009. Cigarettes Butts and the Case for an Environmental Policy on Hazardous Cigarette Waste. Int. J. Environ. Res. Public. Health 6, 1691-1705.

Pelit, F.O., Demirdöğen, R.E., Henden, E., 2013. Investigation of heavy metal content of Turkish tobacco leaves, cigarette butt, ash, and smoke. Environ. Monit. Assess. 185, 94719479.

Raper, J.A., Amal, R., 1993. Measurement of Aggregate Fractal Dimensions Using Static Light Scattering. Part. Part. Syst. Charact. 10, 239-245.

Ringenbach, E., Chauveteau, G., Pefferkorn, E., 1995. Effect of soluble aluminum ions on polyelectrolyte-alumina interaction. Kinetics of polymer adsorption and colloid stabilization. Colloids Surf. Physicochem. Eng. Asp. 99, 161-173.

Sau, T.K., Rogach, A.L., Jäckel, F., Klar, T.A., Feldmann, J., 2010. Properties and applications of colloidal nonspherical noble metal nanoparticles. Adv. Mater. 22, 1805-1825. Slaughter, E., Gersberg, R.M., Watanabe, K., Rudolph, J., Stransky, C., Novotny, T.E., 2011. Toxicity of cigarette butts, and their chemical components, to marine and freshwater fish. Tob. Control 20, i25-i29.

Ter Halle, A., Jeannau, L., Martignac, M., Jardé, E., Pedrono, B., Brach, L., Gigault, J., 2017. 
420 Nanoplastic in the North Atlantic Subtropical Gyre. Env. Sci Technol in press.

421 van Dijk, W.D., Gopal, S., Scheepers, P.T.J., 2011. Nanoparticles in cigarette smoke; real-

422 time undiluted measurements by a scanning mobility particle sizer. Anal. Bioanal. Chem. 399,

$423 \quad 3573-3578$.

Velzeboer, I., Kwadijk, C.J.A.F., Koelmans, A.A., 2014. Strong sorption of PCBs to nanoplastics, microplastics, carbon nanotubes, and fullerenes. Environ. Sci. Technol. 48,

$427 \quad 4869-4876$.

Waeles, M., Tanguy, V., Lespes, G., Riso, R.D., 2008. Behaviour of colloidal trace metals $430(\mathrm{Cu}, \mathrm{Pb}$ and $\mathrm{Cd})$ in estuarine waters: An approach using frontal ultrafiltration (UF) and 431 stripping chronopotentiometric methods (SCP). Estuar. Coast. Shelf Sci. 80, 538-544.

Wang, L., Fortner, J.D., Hou, L., Zhang, C., Kan, A.T., Tomson, M.B., Chen, W., 2013. Contaminant-mobilizing capability of fullerene nanoparticles (nC60): Effect of solventexchange process in nC60 formation. Environ. Toxicol. Chem. 32, 329-336. 
Highlights:

- Cigarette butts (CGB) are the most common litter found in the environment.

- This study presents new evidence of nanoscale particles (NP) leached from CGB.

- NP contain a large part of the volume of metal released from CGB.

- Our results raised urgent questions on CGB litter and their environmental impacts. 